\title{
Soft Systems Methodology for Hard Systems Engineering - The Case of Information Systems Development at LIT/INPE/BRAZIL
}

\author{
Ana Claudia de Paula Silva ${ }^{1}$, Geilson Loureiro ${ }^{1}$
}

\begin{abstract}
The Soft Systems Methodology (SSM) was developed to deal with soft systems, systems in which the human components predominate. Any kind of software is a hard system, since technical factors predominate in it. But when the software is a component of an Information System its success depends heavily on soft aspects. This paper analyzes the potential contribution of SSM to Software Engineering in order to propose a method to support requirements elicitation for the development of Information System that helps to understand and consider the human, social and political factors that will influence the system success. A real situation of the Integration and Testing Laboratory (LIT) of INPE (Brazilian Institute for Space Research) was used to perform the study and to exemplify the use of the proposed method.
\end{abstract}

\section{Keywords}

Information Systems; Requirements Engineering; Software Engineering; Soft Systems Methodology; Systems Engineering.

\footnotetext{
${ }^{1}$ A.C. Silva, G. Loureiro ( $\left.\square\right)$

Technological Institute of Aeronautics (ITA), Praça Marechal Eduardo Gomes, 50, Vila das Acácias, São José dos Campos, São Paulo, Brazil and Integration and Testing Laboratory, Brazilian Institute for Space Research, Av. Astronautas, 1758, CEP: 12227-010, Jardim da Granja, São José dos Campos, São Paulo, Brazil e-mail: \{anaclaudia, geilson\}@lit.inpe.br
} 


\section{Introduction}

Certain kinds of software, those that are components of Information Systems, are custom built to support business processes of an organization. They are software used, for example, to assist decision-making and to carry out business operations.

This type of software, even having the functions desired by the stakeholders, may not meet expectations if people do not perform certain actions or perform them in a wrong way. Its success depends heavily on the action of people. For this reason, to obtain requirements to built a software for an Information System, besides understanding the business process that will be supported by it, it is important to be able to see and understand the various views and interests that exist within an organization and consider the human and subjective aspects of the environment in which the software will be used.

Techniques used in Software Engineering, such as scenarios and use cases, focus on the interactions with the system (Sommerville 2011). There is a lack of methods and techniques that help the understanding of the above mentioned aspects.

Outside the realm of Software Engineering, Soft System Methodology (SSM) proposes to work these issues. The word "soft" from SSM is opposed to the term "hard" from systems addressed by the traditional Systems Engineering, systems in which technical factors predominate. In soft systems the human components predominate. Although a software is a "hard" system, when it is part of an Information System "soft" aspects have a great weight to its success. Therefore, it is not strange that SSM can contribute in this area.

This paper analyzes the potential contribution of SSM to Software Engineering in order to propose a method to support requirements elicitation for development of Information Systems that helps to understand the various views and interests existing in an organization and that consider the human, social and political factors that will influence the system. A real situation of the Integration and Testing Laboratory (LIT) of INPE (Brazilian Institute for Space Research) was used to perform the study and to exemplify the use of the proposed method.

The paper presents in Section 2 the traditional Information System Development (ISD). Section 3 presents an overview about SSM. Section 4 presents and exemplifies the proposed method. Section 5 discusses the results and Section 6 draws some conclusions.

\section{Traditional Information Systems Development (ISD)}

The software development process is commonly divided into phases. Different authors, for example Pressman (2011), Sommerville (2011) and Young (2004), organize and name these phases in different ways. But generally these phases in- 
clude activities intended to: understand what will be developed; design; implement; test; and maintain the software. At a high level, the basic activities of this process are: specification, development, validation and evolution.

Specification is the process of understanding and definition of services that the system should provide and of identifying constraints to their development and operation; that is, the process of understanding, identifying and definition of system requirements. Development is the process of converting a system specification into an executable system. The validation process is intended to verify that system meets real customer needs. The evolution process is concerned with changing the system during its lifetime in response to changes in customer needs (Sommerville 2011).

The specification process is considered one of the most crucial stages in software development (Sommerville 2011, Aurum and Wohlin 2005, Castro et al. 2002) as it addresses the critical problem of designing the right software for the customer. To deal with specification process, the Software Engineering makes use of the Requirements Engineering.

Common Requirements Engineering activities are elicitation, analysis, documentation, negotiation, verification and validation, change management and track of requirements of a system (Sommerville 2011, Aurum and Wohlin 2005, Pressman 2011, Young 2004).

This research intends to contribute to the requirements elicitation activity.

Requirements elicitation is concerned with learning and understanding the needs of users and project sponsors with the ultimate aim of communicating theses needs to the system developers (Aurum and Wohlin 2005, p. 21)

Traditionally, Requirements Engineering presents a range of techniques for requirements elicitation. The techniques considered more effective by Young (2004) are: interviews; document analysis; brainstorming; requirements workshops; prototyping; use cases; storyboards; interface analysis; modeling; performance and capacity analysis; and scenarios.

\section{Soft Systems Methodology (SSM)}

This section presents an overview about Soft Systems Methodology (SSM) according to Checkland and Scholes (1999) and Checkland and Poulter (2006).

SSM was designed and developed from an action research program at the University of Lancaster, started in 1969, which aimed at applying the ideas of the Systems Thinking in addressing organizational problems.

Overall, the process proposed by SSM seeks to give a certain intellectual rigor to the subjective characteristic of human affairs. It is a flexible and organized process, based on system ideas to deal with situations that one sees as problematical, so that actions to improve can be taken. 
The SSM approach is based on two features present in every problematical situation: the existence of conflicts of worldviews, particular ways as each person sees the world, and the fact that we always have people trying to act purposefully.

Briefly, given a problematical situation, SSM proposes a Cultural Analysis and a Logic-Based Analysis to identify desirable and feasible changes on it.

To perform the Cultural Analysis, SSM suggests four ways: use Rich Pictures to view the situation and perform the analysis One, Two and Three.

The use of Rich Pictures consists of representing by pictures as the inquirer is perceiving the situation in question. These pictures are then presented to those involved in the situation in order to facilitate them to identify errors or omissions in what was perceived.

Analysis One is an analysis of the intervention itself and consists of thinking about who are in the roles "client" and "practitioner" and who could usefully be included in the list of "issue owner". According to the authors mentioned above: Client is the person, or group of persons, who caused the intervention to happen; Practitioner is the person, or group of persons, conducting the investigation, and Issue Owner are the people who can be regarded as being concerned about or affected by the situation and the outcome of the effort to improve it.

Analysis Two aims at getting a sense of the social texture of the situation by using a model consisting of three elements, namely:

- Roles: Social positions, formally recognized or not, which mark differences between members of a group or organization. Example: department heads.

- Norms: The expected behaviors associated with, and helping to define a role.

- Values: The criteria by which behavior-in-role gets judged.

The Analysis Three is a political analysis, which seeks to get a feeling about the distribution of power in the social situation through questions like: What one have to possess to be powerful in this group or organization? Knowledge? Charisma? Skills? Experience? Rudeness? Commitment? Etc.

The Logic-Based analysis consists of modeling purposeful action as a system, a human activity system.

A logically linked set of activities constitute a whole - its emergent property being its
purposefulness. The activities concerned with achieving the purpose (the operations) are
monitored against defined measures of performance so that adaptive control action (to
make changes) can be taken if necessary (Checkland and Poulter 2006, p. 10).

Each model is built to express a particular worldview, and to be used as a source of questions to ask about real-world situation, structuring a debate about desirable and feasible changes. These models are not model of a real-world activity, they are models considered relevant to debating it. Fig. 2 illustrates an SSM model. Note that the arrows indicate dependency. Activities that have arrow to them are dependent on the activity in which the arrow originates.

To build a model, SSM proposes to write a statement, called Root Definition (RD), describing the activity system being modeled. This statement is constructed around an expression of a purposeful activity as a transformation process. 
The PQR formula provides a shape for $\mathrm{RD}$ : do $\mathbf{P}$, by $\mathbf{Q}$, in order to help achieve R. P answer the question "what?", Q the question "how?" and R "why?".

To help build the model SSM suggests that RD is enriched with other elements: the decision to build a model whose boundaries cut across organizational boundaries (Issue-based models) or not (Primary Tasks models); the elements of CATWOE analysis; and the measures of performance by with the operation of the system would be judged.

The elements of CATWOE analysis are:

- C (Customers): People who are beneficiaries or victims of the transformation (T);

- A (Actors): People to do the activities which make up the transformation (T);

- T (Transformation process): Transformation of an entity into a different state of form;

- W ("Weltanschauung"): The worldview which makes this $T$ meaningful in context;

- O (Owner): Those who could stop T;

- E (Environmental Constraints): Elements outside the system which it takes as given.

Measures of performance can be expressed through the 3Es:

- Criteria of Efficacy (E1): This transformation is producing the desired output?

- Criteria of Efficiency (E2): This output is obtained using minimum resources?

- Criteria of Effectiveness (E3): This transformation is worth doing because it makes a contribution to some higher level or longer-term aim?

The objective of the process of SSM is to identify changes that are systematically desirable (based on the model) and culturally feasible (for these people in their situation). Implement changes alters the current situation and the cycle starts again.

\section{SSM Applied to Information Systems Development (ISD)}

This section presents the proposed method. To perform the study that led to this method we used a real situation of the Integration and Testing Laboratory (LIT) of INPE (Brazilian Institute for Space Research).

LIT has been specially designed and built to meet the needs of the Brazilian Space Program and conducts assembly, integration and testing of satellites. Also, LIT offers enabling products and services of space product development to companies interested in qualifying and improving their products. The research occurred in the context of the process of providing services to industry.

In the following, this paper presents the proposed method, its relation with SSM and some examples. It is a guide with ten tasks to be performed, but one can 
always feed back to add new information obtained during the process. The input to this method is a request to develop an Information System to support a particular business process.

Task 1: Preliminary Definitions Task 1 consists of defining who is in the roles of client and requirements engineer.

In software engineering the requestor is called client (Somerville 2011, Pressman 2011). SSM also presents the concept of client and there is no conflict between these definitions, being the definition of Software Engineering just more detailed for some authors.

Who leads the work of requirements engineering is called in Software Engineering "requirements engineer". Also there is no conflict between this definition and the definition of the term "practitioner" from SSM.

In case of LIT the client is the head of LIT and the information systems development team is in the role of requirements engineer.

Task 2: Business Process Vision This task consists of understand the business process that will be supported by the system. Various techniques of requirements engineering can be used for this purpose, such as interviews, observation, reading documents.

This method proposes the additional use of Rich Pictures as tools to aid understanding and a textual description to express the view of the process on which the requirements elicitation activity is being conducted.

Fig. 1 shows an example of a Rich Picture used in the case of LIT.

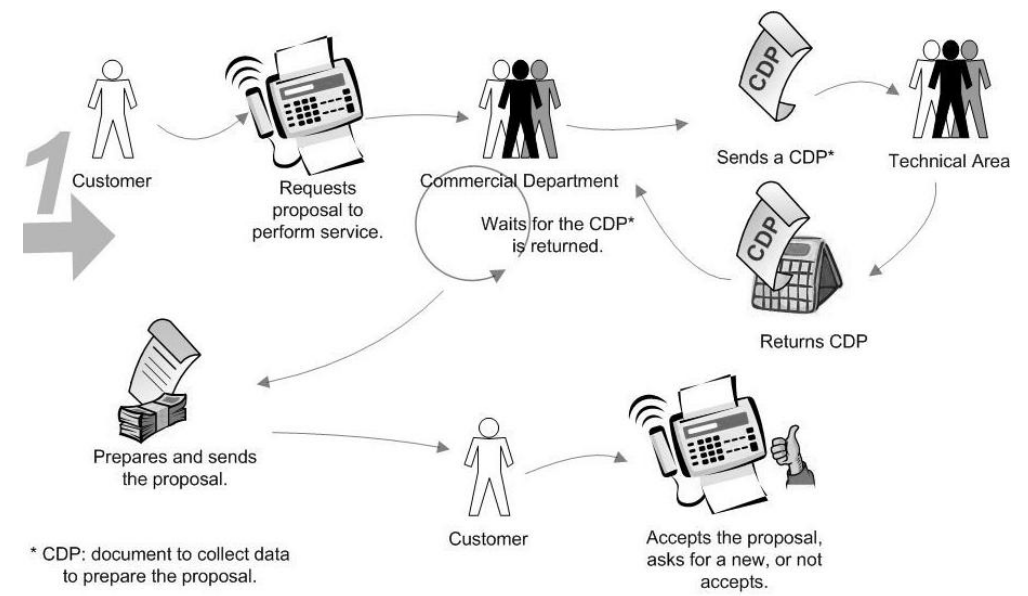

Fig. 1 One of the Rich Pictures used in the LIT case

Task 3: Analysis of Stakeholders in the Social Context This task consists of listing the identified stakeholders and analyze them in the social context in which the Information System is or will be inserted. 
In Software Engineering "stakeholder" is defined as a person or role that, somehow, is affected by the system (Sommerville 2011).

Stakeholders that contribute most to define the operational details of the software are the ones who will actually use the software, these are called "end users" in Software Engineering (Pressman 2011). But it is also important to consider other stakeholders. At this point, proved to be useful thinking about the concept of "Issue Owner" from SSM. Thinking about the people interested or affected by the business process and by the result of efforts to improve it contributes to compiling the stakeholders list.

Referring to the analysis of stakeholders, SSM's main contribution comes from Analysis Two which proposes a cultural research through the identification of roles, norms and values.

Table 1 presents a format for documenting this analysis and some examples from the LIT case.

Task 4: Political Analysis This task is performed in order to get a feeling about the distribution of power in the environment in which the Information System is or will be inserted. This analysis corresponds to the Analysis Three from SSM and contributes to guide the efforts towards a solution that is "culturally feasible".

An example from the case of LIT is that technical areas that generate more revenue have higher influence in decision-making.

Task 5: Definition of the Activity System This task consists of thinking about the business process that will be supported by the Information System as a transformation process as defined by SSM (element T of the CATWOE analysis) and writing a statement describing the essential definition of the activity system to achieve this transformation.

To write this statement this method proposes answering the questions of the elements $\mathrm{P}$ and $\mathrm{R}$ of the $\mathrm{PQR}$ formula from SSM, being that the models that will be built to the activity system will answer the question of the element Q (How?).

An example from the LIT case would be as following:

$\mathrm{T}$ : "Service requested by the industry to LIT" into "Service performed by LIT or justifiably not performed".

Definition of the activity system: A system to provide services requested by enterprises outside INPE interested in qualifying and improving their products $(\mathrm{P})$ in order to help LIT to generate additional financial resources needed to keep the laboratory operation $(\mathrm{R})$.

Task 6: Identification of Environmental Constraints This task is performed in order to identify the constraints imposed by the environment in which the activity system is inserted, as proposed by SSM. It is about the element E of the CATWOE analysis.

An example from the case of LIT is that one must consider that the same technical areas that perform services for enterprises outside INPE also have to meet the service demands of other departments of INPE and also of LIT. 
Task 7: Building Models This task consists of building a model that represents the activity system that performs the transformation described above, i.e. it represents the business process that will be supported by the information system.

Even working with a single transformation, a single RD, it is common that there is conflict about which activities are necessary and how these activities should be organized to accomplish the transformation. Several models can be constructed to depict and discuss the different views until you reach an acceptable model for the various stakeholders that will be used as a basis for requirements elicitation.

Fig. 2 shows the model that represents the agreement to the case of LIT.

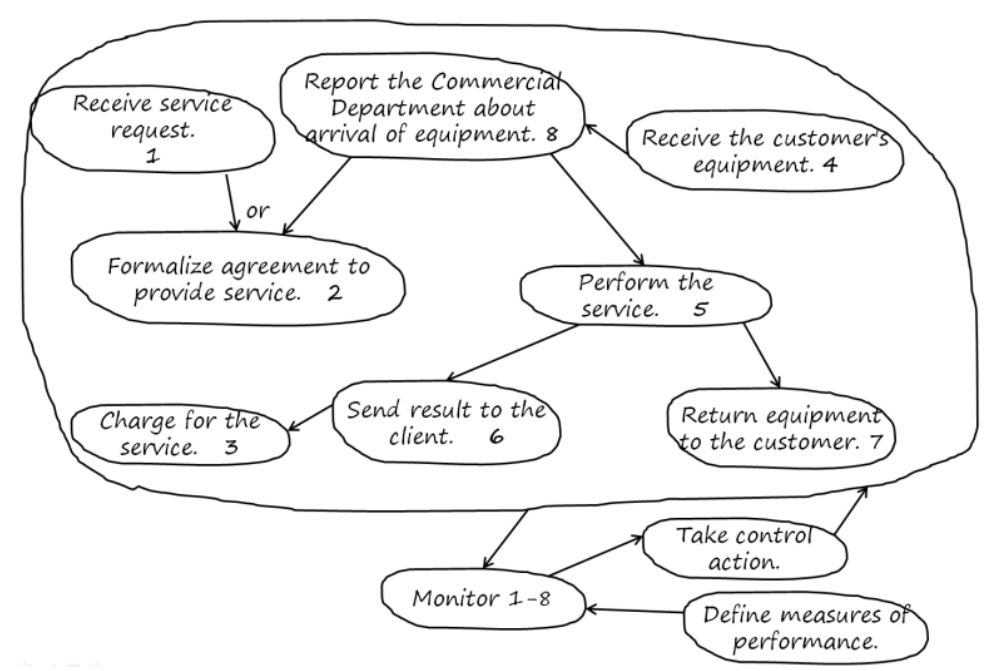

Fig. 2 Activity model to the LIT case

Task 8: Definition of Performance Measures This task consists of defining criteria by which activity system performance will be judged (3Es from SSM); how the information system should contribute to each E; and who will monitor whether the information system is contributing. A example from LIT case would be as following:

E2: The services requested by customers are being carried out within reasonable time and with minimum use of resources, as judged from the head of the LIT?

Contribution expected from the Information System: Reduce the time spent on bureaucratic tasks; reduce the use of human resources.

People to monitor: Quality team.

Task 9: Analysis of the Activities of the Model It is important for requirements elicitation to understand how each activity of the model is currently done, what problems are reported by the stakeholders and how they visualize improvements 
in these activities. Much of this understanding is obtained throughout the whole previous analysis, particularly of the effort to build the model.

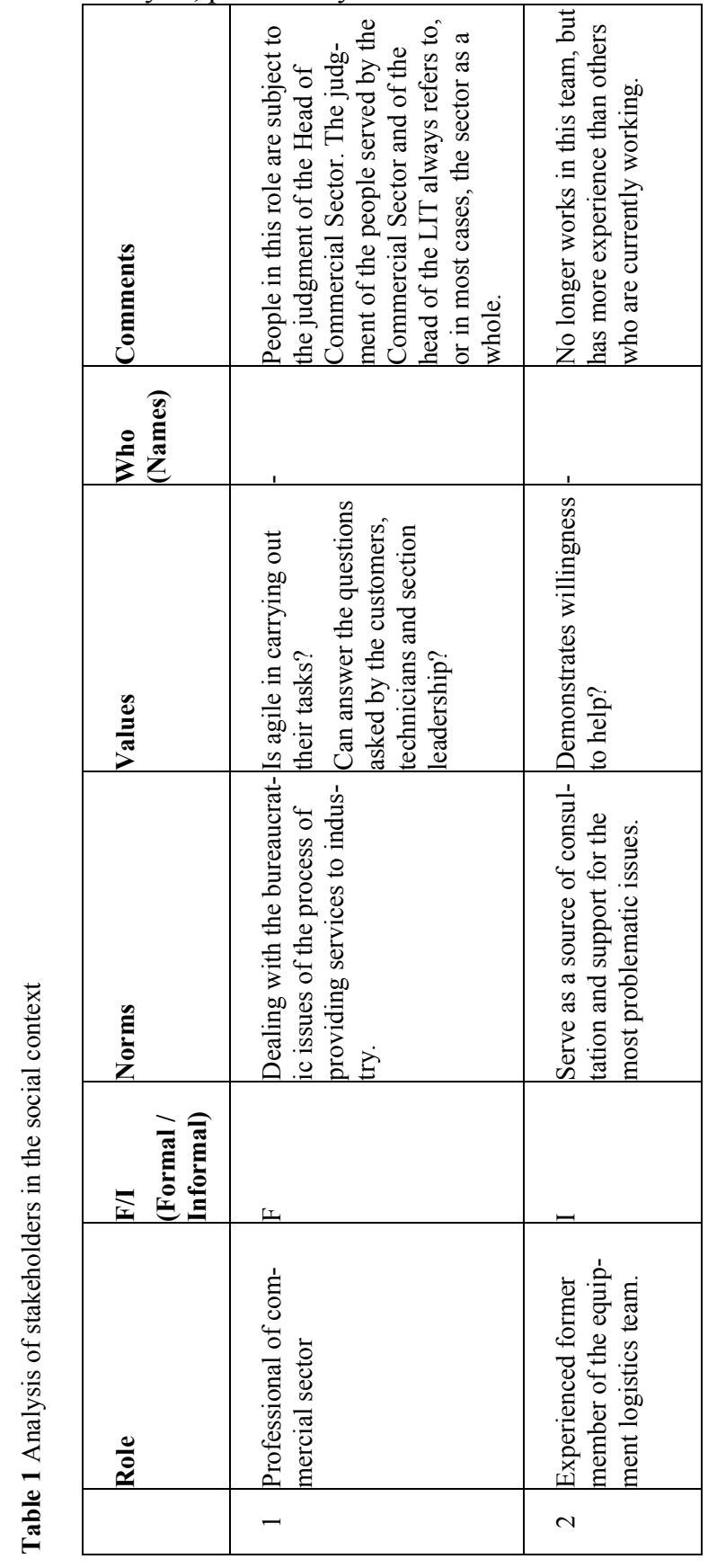


This task is to discuss a little more each activity and consolidate the understanding in a table that will serve as an information source for the requirements elicitation. At this point, it is interesting to identify who are the people who will do each activity. They correspond to the element "A" from de CATWOE analysis.

An activity still considered too complex to be analyzed must be broken down and then analyzed through the method as a sub-system. In the case of LIT the activities 2,3,4 and 5 of the model shown in Fig. 2 were broken down and analyzed as sub-systems.

Task10: Requirements Elicitation Task 10 consists of writing preliminaries requirements for the Information System. This method proposes that requirements elicitation is guided by the questions presented in Table 2 .

\section{Discussion}

Indeed, SSM addresses aspects not covered by the Requirements Engineering and can contribute to it. At the same time, some aspects and concepts of SSM have equivalence with the ones of the traditional Requirements Engineering. This study attempted to add to Requirements Engineering soft aspects not covered traditionally by it.

The method allows to better understand the cultural aspects of the environment where Information System is used, what is important since the requirement engineer will have to mediate conflicts and propose solutions. Some alternatives of solution may represent the most logical, or cheapest or most efficient solution, but faced with certain situations, they simply would not work because the success of the Information System have a strong dependence of the action of people and human behavior is not always logical.

Understanding the distribution of power helps drive the efforts towards a culturally feasible solution. If, for example, a stakeholder who has some kind of power in the organization demonstrates resistance to solution presented, it may signal that this is not a feasible solution or that a further effort to demonstrate the benefits of using the proposed Information System will be needed to break that resistance.

Also, it is important to emphasize that sometimes in organizations there is not a well-defined process to achieve what one wants, the activities are confusing so that they cannot be met by an Information System. Other times there is no clarity about what one wants to do or activities are conducted in a manner inconsistent with the purpose of the business process as a whole. To think about this process as a transformation process and to draw the activities in a logical model brings out this kind of problem and provides an opportunity to identify this confusion and, inevitably, to seek improvement. 
Table 2 Questions to guide the requirements elicitation

\begin{tabular}{|c|c|c|}
\hline Question & Comments & Example \\
\hline $\begin{array}{l}\text { What are the } \\
\text { stakeholders ex- } \\
\text { pectations regard- } \\
\text { ing the Information } \\
\text { System? }\end{array}$ & $\begin{array}{l}\text { Stakeholder expectations should } \\
\text { guide the requirements gathering. } \\
\text { The analysis of stakeholder in the } \\
\text { social context (Task } 3 \text { ) says much } \\
\text { about those expectations. They are } \\
\text { related to the stakeholders roles in } \\
\text { the organization. Everyone expects } \\
\text { the Information System to help } \\
\text { them have a positive judgment on } \\
\text { the role they occupy. }\end{array}$ & $\begin{array}{l}\text { For someone in the "professional } \\
\text { of the commercial sector" role the } \\
\text { Information System is expected to } \\
\text { help them execute their tasks faster } \\
\text { and to provide reliable reports } \\
\text { about the process. }\end{array}$ \\
\hline $\begin{array}{l}\text { What information } \\
\text { do stakeholders } \\
\text { expect to extract } \\
\text { from Information } \\
\text { System? }\end{array}$ & $\begin{array}{l}\text { The expectations regarding the in- } \\
\text { formation must be consistent with } \\
\text { the purpose of the system. The def- } \\
\text { inition of the activity system (Task } \\
\text { 5) helps keep the focus in this } \\
\text { sense. }\end{array}$ & $\begin{array}{l}\text { The head of LIT expected to know } \\
\text { the income expected for the next } \\
\text { month. }\end{array}$ \\
\hline $\begin{array}{l}\text { What the stake- } \\
\text { holder shall be } \\
\text { able to do in the } \\
\text { Information Sys- } \\
\text { tem to perform } \\
\text { each activity from } \\
\text { the activity model? } \\
\text { (Stakeholder Re- } \\
\text { quirements) }\end{array}$ & \multirow{2}{*}{$\begin{array}{l}\text { Given the expectations, the ques- } \\
\text { tion is how the system will support } \\
\text { each activity of the model defined } \\
\text { for the activity system. Since the } \\
\text { software is part of an Information } \\
\text { System, and because of this its } \\
\text { success depends heavily on the ac- } \\
\text { tion of people, this method propos- } \\
\text { es that for each stakeholder re- } \\
\text { quirement, requirements to be met } \\
\text { by people so that the software can } \\
\text { provide the expected result are also } \\
\text { written. These requirements are } \\
\text { called here organization require- } \\
\text { ments, while the requirements for } \\
\text { the construction of the software are } \\
\text { called product requirements. }\end{array}$} & $\begin{array}{l}\text { Some example for the activity } \\
\text { "Request data to develop the pro- } \\
\text { posal" from the sub-system "For- } \\
\text { malize agreement to provide ser- } \\
\text { vice". } \\
\text { Stakeholder requirement: The } \\
\text { commercial sector shall be able to } \\
\text { check the list of services provided } \\
\text { by each technical area. }\end{array}$ \\
\hline $\begin{array}{l}\text { What the system } \\
\text { (product + organi- } \\
\text { zation) must do to } \\
\text { meet each stake- } \\
\text { holder require- } \\
\text { ment? (System } \\
\text { Requirements) }\end{array}$ & & $\begin{array}{l}\text { Product requirement: The system } \\
\text { shall display the list of services } \\
\text { provided by each technical area. } \\
\text { Organization requirement: The } \\
\text { technical areas shall keep their list } \\
\text { of services updated. }\end{array}$ \\
\hline $\begin{array}{l}\text { What the system } \\
\text { must do to mini- } \\
\text { mize the impacts } \\
\text { of conflicts of in- } \\
\text { terest in its suc- } \\
\text { cess? }\end{array}$ & $\begin{array}{l}\text { This method considers that cultural } \\
\text { aspects can generate requirements } \\
\text { and proposes to write also these } \\
\text { requirements that emerge from cul- } \\
\text { tural analysis. They are require- } \\
\text { ments concerned with accommo- } \\
\text { dating conflicts of interest that may } \\
\text { interfere in the expected result of } \\
\text { the system. }\end{array}$ & $\begin{array}{l}\text { Staff of the commercial sector ex- } \\
\text { pects the system to provide infor- } \\
\text { mation on the progress of services } \\
\text { so they can inform the customer } \\
\text { when requested. It is not the cul- } \\
\text { ture of some technical areas of LIT } \\
\text { to give feedback to the Commer- } \\
\text { cial Sector of the status of services. } \\
\text { So it is not enough fields in the } \\
\text { system interface to be fulfilled by } \\
\text { the technical areas. They would not } \\
\text { be. A product requirement to force } \\
\text { this communication could be gen- } \\
\text { erate a public report on the services } \\
\text { that are running in each area. }\end{array}$ \\
\hline
\end{tabular}


And, since the Information System must contribute to the performance of the business process, it is important to define how this performance will be judged and to monitor if the Information System is providing any contribution.

Also, it was shown to be useful the analysis of the activities of the model (task 9) principally for highlighting requirements that were not clearly stated by the stakeholders.

\section{Conclusion and Further Work}

When an information system is requested, the solution is not just product. The proposed method leads the requirements engineer to think in and to document in advance the actions to be performed by people for ensure that the expectations about the system are met.

Also, it induces the requirements engineer to pay more attention to the subjective questions and to the conflicts of interest and to what is behind them, and directs the Information System design for a balanced solution, easier to be accepted and effectively utilized.

The result of this work is aligned with the initial goal. But this is a first version that can be improved by applying the method in other cases of Information Systems development. This is a further work to be done, as well as investigating how SSM can contribute to the development of other types of hard systems that are also developed to be used by people.

\section{References}

Aurum A, Wohlin C Eds (2005) Engineering and Managing Software Requirements. SpringerVerlag, Berlin

Castro J, Kolp M, Mylopoulos J (2002) Towards requirements-driven information sytems engineering: the Tropos project. Elsevier Science Ltd.

Checkland P, Poulter J (2006) Learning for Action. John-Wiley \& Sons, Chichester

Checkland P, Scholes J (1999) Soft Systems Methodology in Action. John-Wiley \& Sons, Chichester

LIT (2012) Home Page of the Integration and Testing Laboratory (LIT) of the Brazilian Institute for Space Research (INPE). Available in: http://www.lit.inpe.br. Accessed 10 January 2012.

Pressman R S (2011) Engenharia de Software, Uma abordagem Profissional. McGraw-Hill, New York

Sommerville I (2011) Engenharia de Software. Pearson Prentice Hall, São Paulo

Young R R (2004) The Requirements Engineering Handbook. Artech House, Inc., Norwood 